\title{
Contraditório, mas coerente
}

\author{
Marcos Rogério Cordeiro \\ Universidade Federal de Minas Gerais
}

Resumo: Este estudo propõe analisar a obra de Antonio Candido, Formação da literatura brasileira, a partir de sua articulação global, marcada pela combinação de pontos de contradição e sua exposição coerente.

Palavras-chave: crítica literária, historiografia, dialética

\begin{abstract}
Por coerência, entende-se aqui a integração orgânica dos diferentes elementos e fatores, formando uma diretriz, um tom, um conjunto, cuja descoberta explica a obra como fórmula, obtida pela elaboração do escritor. É a adesão recíproca dos elementos e fatores, dando lugar a uma unidade superior; mas não se confunde com a simplicidade, pois uma obra pode ser contraditória sem ser incoerente, se suas condições forem superadas pela organização formal.
\end{abstract}

Formação da literatura brasileira segue um plano inteligente, ao combinar, de um lado, um conjunto vasto e variado de livros e autores, exposto com atenção para o detalhe e sua articulação, marcada essa por impasses, oposições, depurações e ajustamentos sucessivos, e, de outro, uma linguagem clara e corrente que acompanha pari passu tais movimentos e os elucida por dentro. O livro

1. CANDIDO. Formação da literatura brasileira: momentos decisivos, p. 39. Daqui por diante, para agilizar a leitura, as referências ao livro serão feitas no corpo do texto, com indicação da página. 
apresenta, de modo coerente, a contradição imanente do assunto, fazendo com que um processo (a "formação") se mostre em ato. Talvez por isso - e não só por isso - Formação se pareça menos com livro de história da literatura e mais com aqueles que chamam de "intérpretes do Brasil", apesar do seu tamanho e conteúdo. Neste ponto, inclino-me a concordar com alguns estudiosos que viram na obra uma chave de explicação da história passada e presente do país, reconhecendo nela o fôlego da reflexão e o pendor ensaístico que se desenvolvem a partir de problemas escolhidos de acordo com a função explicadora que possuem. ${ }^{2}$ Esse método de exposição e análise não se impõe ao objeto (o conjunto de livros e autores), ordenando-o ou estabelecendo vínculos, mas é construído por ele, que delimita a contradição apontada. Por esse motivo, defendo aqui que a história social, tomada em sua acepção ampla e concreta, prefigura o método de exposição e interpretação da literatura, e nisto consiste a particularidade do livro, que dá volta no historicismo que predomina nesse tipo de trabalho.

Tratarei dessas questões de maneira indireta, focalizando a atenção em dois aspectos correspondentes: primeiro tentarei mostrar que o crítico utiliza de maneira sistemática - conceitos antitéticos, permitindo que a contradição própria das coisas se estruture; depois buscarei acompanhar em linhas gerais o processo de formação da literatura, procurando interpretar o padrão de análise adotado.

\section{Conceitos sob o fundo histórico}

As disciplinas ligadas à arte e à história são introduzidas na Formação seguindo um programa de construção: estilística, close reading, sociologia da cultura, economia política etc. são entrepostas com interesse pela análise das produções literárias e dos fatos sociais que nelas penetram. Frente a tudo isso, a dialética comanda. O próprio autor, no prefácio de Tese e antítese - cujo título chama à baila o problema de que estou tratando - torna clara sua concepção de crítica como uma atividade propriamente dialética: "Envergando uniforme adequado (pois é sempre uma espécie de casaca-de-ferro da literatura), o crítico se imagina um Asmodeu dialético e abre as caixas." ${ }^{3}$ Por sua vez, o leitor com espírito crítico

2. Nessa linha de reflexão, ver: ARRIGUCCI. Movimentos de um leitor; SCHWARZ. Os sete fôlegos de um livro; e ARANTES. Providências de um crítico na periferia do capitalismo.

3. CANDIDO. Tese e antítese, p. III. 
reconhece que tudo no livro se organiza e se torna inteligível por meio de uma exposição que exprime o estado de oposição das coisas. Trata-se aqui de um princípio estruturador da análise que, sem desconhecer que a "obra é uma realidade autônoma" (p. 35), não descuida de que seja também uma "expressão da realidade" (p. 27). A junção desses dois princípios - não a sobreposição ou combinação, mas a reciprocidade metodológica - representa um salto qualitativo que divide o parecer da crítica sobre o livro. ${ }^{4} \mathrm{~A}$ acepção que guia a análise parece inequívoca nas palavras do autor, ao trocar em miúdos seu próprio método:

A compreensão da obra não prescinde a consideração de elementos inicialmente não-literários. O texto não os anula, ao transfigurá-los e, sendo um resultado, só pode ganhar pelo conhecimento da realidade que serviu de base à sua realidade própria. Por isso, se o entendimento dos fatores é desnecessário para a emoção estética, sem o seu estudo não há crítica, operação essencialmente de análise, sempre que pretendemos superar o impressionismo.” (p. 36)

O que pretendo mostrar aqui é, primeiramente, a disposição dialética que preside a análise, operação que se realiza por meio do uso de conceitos opositivos, e, em segundo lugar, que a razão dessa disposição se justifica pelo exercício crítico propriamente dito, atendendo às premissas estéticas de uma obra e o modo como ela internaliza e encaminha questões de ordem histórico-social. Segundo meu ponto de vista, essas proposições se encontram imbricadas e a disposição que passam a ter (dialética) se deve à forma própria dos objetos em análise (as obras e a sociedade). O uso de conceitos - o método, em suma - se faz de maneira imanente, podemos dizer, pois ele como que apreende e torna suas as premissas daquilo que analisa. Nesse caso, é a ordem dos ditos objetos que delimita os meios de sua compreensão. Retomando as palavras do próprio crítico: "A minha tendência é a de todo o nosso grupo de Faculdade: fomos animados pelo que denominei paixão do concreto. Em literatura, por exemplo, sou muito preso à realidade do texto."

4. Apesar de reconhecer a singularidade de cada trabalho, podemos reunir, de um lado, Paulo Arantes e Roberto Schwarz, já citados, além de Leopoldo Waizbort, e, de outro, Afrânio Coutinho, Haroldo de Campos, Luiz Costa Lima e Abel Barros Baptista. As referências completas se encontram no final do artigo.

5. Entrevista concedida a Luiz Carlos Jackson. Ver JACKSON, A tradição esquecida, p. 125. 
Para começar, note-se a força e a função que assume no pensamento do crítico a correlação entre o particular e o universal: "Se fosse possível estabelecer uma lei de evolução da nossa vida espiritual, poderíamos talvez dizer que toda ela se rege pela dialética do localismo e do cosmopolitismo, manifestada pelos modos mais diversos" . Em Formação, lê-se: "Neste livro, tentar-se-á mostrar o jogo dessas forças, universal e nacional, que plasmaram [a literatura] como permanente mistura da tradição européia e das descobertas do Brasil.” (p. 29). Demarcam-se, assim, os contornos e o significado de cada tendência, colocando-as em perspectiva histórica, mostrando a predominância de uma ou outra, não em abstrato, mas como expressão da cultura. A percepção de que existem aí indícios de contradição vai se refazendo em outra direção, procurando compreendê-los no interior de cada um dos pólos e não somente entre eles. Assim, o universalismo aos poucos revela, em si mesmo, características da tendência oposta, problematizando dados nacionais, enquanto o localismo vai engendrando imagens e ideias de caráter geral e universal.

Seguindo esse esquema, note-se que, na Colônia, o Arcadismo se assumiu cosmopolita e universal, "incorporando a atividade intelectual aos padrões europeus" (p. 327). Todavia, o exame interpretativo, atento a modulações e variações da linguagem, mostra o contrário se desenvolvendo no interior mesmo das exigências formais (entendendo aqui a articulação de técnica e assunto) da escola. Ao analisar a poesia de Cláudio Manuel da Costa, por exemplo, Candido reconhece que ele "se arraigou pela inteligência estética [dos] padrões eruditos da Europa", embora fosse, ao mesmo tempo, "o mais profundamente preso às emoções e valores da terra.” (p. 88) Dá-se o mesmo com Tomás Antonio Gonzaga, respeitando e até acentuando, contudo, sua particularidade: "Em nossa literatura é dos maiores poetas, dentre os sete ou oito que trouxeram alguma coisa à nossa visão de mundo. Com ele a pesquisa neoclássica da natureza alcança a expressão mais humana e artisticamente mais pura." (p. 125)

O movimento inverso - o particularismo que vai se descobrindo cosmopolita - também se efetiva, não de maneira isolada, mas como algo constitutivo da dinâmica histórica da cultura. Referindo-se ao Romantismo, que fez da cor local sua razão de ser, Antonio Candido explica: "Tendo-se originado de uma convergência de fatores locais e sugestões externas, é ao mesmo tempo nacional e universal." (p. 332). Porto Alegre, por exemplo, se encontrava ainda

6. CANDIDO. Literatura e cultura de 1900 a 1945. In: Literatura e sociedade, p. 109. 
"preso" aos neoclássicos da última fase, e, junto com Joaquim Norberto, procurou "adaptar ao Brasil a balada romântica, com que alemães e franceses tentavam estilizar temas medievais" (p. 390-391). Semelhante solução pode ser encontrada no Bernardo Guimarães tardio, que buscava o "retorno à harmonia neoclássica." (p. 484) Melhor exemplo dessa complementaridade, com vantagens obtidas no plano da forma, é encontrado na comparação feita entre Gonçalves Dias e Magalhães: enquanto esse ficou em um "meio-termo entre clássicos e ultra-românticos", o outro incorporou melhor e fez seus os recursos poéticos europeus, "por isso, a sua intervenção consolida estruturalmente o Romantismo brasileiro". (p. 376)

Saindo um pouco do campo estrito da cultura - no qual os conceitos de localismo e universalismo podem ser manejados mais propriamente - e deslocando para o da estética, notamos o mesmo uso objetivo de conceitos opositivos. Nesse caso, mimese e realismo são tomados em perspectiva histórica, como sempre, mas com interesse predominante pela forma artística. Repare-se, antes de tudo, o contraste: mimese é compreendida - em acepção reconhecidamente inspirada em Aristóteles, Horácio e Boileau, por exemplo como "imitação literária" (p. 53), isto é, no uso consciente de recursos e temas estabelecidos pela tradição, que empresta profundidade e elevação à obra e reponde por seu mérito artístico; realismo é tomado como procedimento de construção que possibilita a solução artística para as questões do presente. Ora, apesar do aparente esquematismo, que engana, o que o crítico monta é um cruzamento de proposições. Isso não se impõe como teoria nem se resolve nela, mas através dela, ou seja, trata-se, como já foi dito, de um método, cuja práxis se inspira no concreto. Os exemplos vêm do estudo das obras. Na análise de O Uraguai, Candido mostra que, apesar de obediente às convenções impostas pela mimese, o poeta consegue ultrapassar o bucolismo convencional, inserindo particularidades da vida social local: "é a paz virgiliana cantada nas pastorais, em que a presença do trabalho confere dignidade à paisagem, desvinculando-o do pitoresco". (p. 136) Daí reconhecer uma espécie de "realismo dos neoclássicos" (p. 175), mostrando o quanto o respeito ao modelo preconizado pela poética árcade cede, aqui e ali, às pressões incoercíveis do contato direto com a realidade. Quanto aos autores românticos, responsáveis por tornar a literatura mais próxima do dia-a-dia, frequentemente sucumbiam ao "desejo eterno de submeter a realidade ao ideal" (p. 539): quando tratavam do tema indígena, por exemplo, moldavam-no muitas vezes segundo os ideais heróicos dos romances de cavalaria. (p. 403) 
Como se pode ver nos casos acima, é a partir da análise do texto que se formula uma teoria explicadora. O dinamismo próprio desse processo, por sua vez, torna complementares os conceitos apresentados como distintos ou opostos. Essa mesma lógica se impõe na análise dos gêneros: a epopéia, parte orgânica da tradição, passível de imitação, se antepõe e se contrapõe ao romance, expressão artística da modernidade, calcado na originalidade. Também nesse terreno, Antonio Candido descobre, por trás da dessemelhança, a complementaridade (ou viceversa), partindo da análise cerrada das obras de cunho histórico planejado: "há no romance, amplitude e ambição equivalentes às da epopéia; só que em vez de arrancar os homens da contingência para levá-los ao plano do milagre, procura encontrar o miraculoso nos refolhos do cotidiano." (p. 430)

Antes de finalizar este ponto, vale a pena discutir mais um aspecto referente a ele: todos sabem que Formação não possui caráter enciclopédico ou de compêndio, mas sim o objetivo de estudar "apenas" os momentos decisivos de nossa literatura. Na perspectiva teórico-metodológica assumida, ${ }^{7}$ esses momentos se resumem ao Arcadismo e ao Romantismo. Retomando a discussão anterior, essas escolas se afirmam como componentes de uma dinâmica histórica, o que não quer dizer que se encontram subordinadas a ela. Como os planos estilístico e social se correspondem efetivamente, mostrando-se partes constitutivas do mesmo processo, em vez de acentuar a contraposição e rivalidade entre os dois movimentos estéticos, Antonio Candido procurou compatibilizá-los, sem descuidar das particularidades de cada um, ao contrário, explicando a partir delas: "a formação de nossa literatura só adquire sentido vista na inteireza dos dois movimentos solidários: o neoclássico, de integração; o romântico, de diferenciação.” (p. 640) A passagem entre eles se efetiva "sem ruptura radical" (p. 327), demonstrando a dialética que lhe dá forma:

O Classicismo terminou por ser assimilado à Colônia, o Romantismo à Independência - embora um continuasse a seu modo o mesmo movimento, iniciado pelo outro, de realização da vida intelectual e artística nesta parte da América, continuando o processo de incorporação à civilização do Ocidente. (p. 312)

As questões acima podem ser resumidas da seguinte maneira: primeiro, a construção da matéria do livro se faz por mediação dialética, explorando

7. Ver a Introdução do livro, especialmente partes 1 e 3. 
as contradições conceituais, procurando articulá-las; segundo, as contradições nunca são de origem teórica, mas muitas vezes se realizam por seu intermédio; enfim, o ponto de partida e de chegada é invariavelmente a literatura e sua correspondência mutuamente inteligível com a realidade histórica e social, reverberando a "paixão do concreto". Se não há engano de minha parte, esses princípios se constituem como aspectos centrais, que estruturam e dão forma ao método de análise e exposição do estudo. Isso se o dado diferenciador de Formação não for posto em segundo plano ou confundido com outra coisa.

\section{Acumulação paulatina}

Transcorridos mais de cinquenta anos desde a publicação de Formação, o cenário de discussões literárias se encontra muito mudado, com um prestígio crescente das questões teóricas muitas vezes em detrimento - mesmo que involuntário - das análises propriamente ditas. Talvez por isso passe despercebido ao leitor de hoje em que consiste a força do livro, que é a marca do estilo de pensamento do autor: o respeito pelo primado do estético. De fato, Antonio Candido concede grande atenção à literatura, com base na qual desenvolve uma rede complexa de temas, estilos, imagens e idéias, que relaciona com os dados externos, numa reciprocidade esclarecedora. A teoria vem a reboque, abstraindo as relações concretas, emprestando-lhes uma racionalidade nada óbvia e construindo uma explicação. Na já citada "Introdução" - uma aula discreta e pertinente a respeito do uso de teorias e métodos no trabalho de análise - o crítico retoma o mote da "paixão do concreto":

O presente livro é sobretudo um estudo de obras; a sua validade deve ser encarada em função do que traz ou deixa de trazer a respeito. As idéias teóricas que encerra só aparecem como enquadramento para estudar as produções e se ligam organicamente a este desígnio. [...] Esta precedência do estético, mesmo em estudos literários de orientação ou natureza histórica, leva a jamais considerar a obra como produto; mas permite analisar a sua função nos processos culturais. É um esforço para fazer justiça aos vários fatores atuantes no mundo da literatura. (p. 17-18)

A atenção dispensada por Antonio Candido à linguagem, o zelo com que a trata no ato da análise, explicam a importância que ela assume na obra. 
Durante a leitura, percebe-se dois aspectos: a linguagem é compreendida primeiramente como forma de expressão, moldada por disciplina e senso estilístico, sempre carregada de sentidos penetrantes cujas mudanças se fazem a cada instante, renovando a si mesma e a experiência que traz (p. 347); simultaneamente, ela se notabiliza por fazer representar uma realidade maior, que a excede, mas que se torna um de seus elementos essenciais (p. 189). Como é possível observar, são dois aspectos distintos, mas que se coadunam. Essa perspectiva metodológica permite ao crítico percorrer os momentos decisivos partindo sempre da análise das obras literárias para chegar, por seu intermédio, à problematização histórica. Acredito que esse é o ponto diferenciador de Formação em comparação com outros livros de história literária: a história não é um pressuposto de análise, mas um resultado seu. O modo como o crítico encaminha o estudo merece atenção muito maior do que a que proponho a seguir, muito resumida e esquematicamente.

O ponto de partida é o que poderíamos chamar de aclimatação. Trata-se de um processo cujo movimento se apresenta ambíguo, mas com um insuspeito sentido de superação. Antonio Candido acompanha a difícil progressão desse processo, mostrando seus avanços e refluxos. Tome-se o Arcadismo para exemplo e podemos identificar a presença recorrente de imagens que não correspondem à experiência. A ambiguidade, talvez paradoxo, se mostra inerente à poética neoclássica: de um lado, presa às convenções da tradição, que imitava; de outro, constrangida pela necessidade de verossimilhança. Em certo ponto, poetas se viram diante de uma dúvida dualista, tendo que produzir a partir de modelos e da realidade ao mesmo tempo, sendo que ambos - no caso particular do contexto brasileiro pelo menos - se contradiziam mutuamente. Assim, se por um lado eles partiam para generalizações distantes e frias, por outro, foram disciplinando a linguagem na busca por expressão. Ou seja, apesar da contradição, alguns alcançaram uma solução formal em suas obras. As consequências disso ultrapassam significativamente as questões específicas do Arcadismo, permitindo ao crítico compreender uma transformação histórica - de interesse estético, sobretudo que se encontrava em curso:

Talvez seja possível, mesmo, afirmar que a vituperada quinquilharia clássica tenha sido, no Brasil, excelente e proveitoso fator de integração cultural, estreitando com a cultura do Ocidente a nossa comunhão de coloniais mestiçados, atirados à aventura de plasmar no trópico uma sociedade em molde europeu. (p. 73) 
Como é próprio da história - da história cultural e literária, inclusive - a pressão dialética forja a superação de impasses e contradições para, a seguir, repô-los sob nova forma, o que, por sua vez, exigirá novo esforço de superação, com outros autores, outros meios e ideias. No momento posterior, o Romantismo, a situação muda, mas parece que ainda patina diante do mesmo paradoxo. Vale a lembrança de Gonçalves Dias, que, apesar de ainda estilizar dados da experiência objetiva segundo modelos externos e extemporâneos (p. 403), encontrou uma maneira de superar as mencionadas ambiguidades através do "caráter nacional do seu lirismo". (p. 409) Como resultado, se por um lado ainda cultiva o gosto quinhentista ou neoclássico, por outro, ele o subjuga à poética romântica (p. 407408), que se impõe no plano da forma: "O índio de Gonçalves Dias não é mais autêntico do que o de Magalhães ou o de Norberto pela circunstância de ser mais índio, mas por ser o mais poético". (p. 405)

Como se pode ver, aclimatação não é um resultado, mas um processo. O fato de reaparecer depois de já superada não nega isso, nem quer dizer que não existiram rupturas. Existiram, mas elas mesmas repõem o problema, modificado embora, que exige, por sua vez, novas formas de solução. A aclimatação é um desiderato histórico, sentido também em outras esferas da vida social, que dispara as mudanças e cria a necessidade de atualização estética da forma, criando também as condições para que se desenvolva um processo maior, que abrange o anterior, a acumulação. Trata-se, nesse caso, de um decurso paulatino, que transcorre muito lentamente e cheio de impasses, recuos e saltos, representando, em sua totalidade, as condições objetivas de adensamento e depuração. O leitor acostumado à prosa linear dos livros de história literária, talvez não perceba que, por trás daquela organização sequencial de autores que encontramos em Formação-e que parece, apenas parece, reproduzir o historicismo dominante - se encontra estruturada uma rede de problemas que organiza cada momento, pondo-os em relação.

Deixo aqui de lado a tão conhecida tese da "literatura como sistema", integrando autores, obras e público, para me concentrar na linha de transmissão estabelecida entre autores próximos e distantes, pela via da formação do gosto e do talento. O ponto de partida é Cláudio Manuel, mas as influências que recebeu e a linguagem que adotou entram na análise. Esse início não condiz com a visão do crítico sobre a literatura brasileira, mas atende ao seu objetivo de exposição. A discussão que nasce daqui a respeito da pertinência da poética barroca na tradição literária brasileira não é irrelevante, mas está fora de foco, pois a questão do livro é estudar o processo de formação "orgânica" da nossa literatura e não a sua história. 
Nem por isso o Barroco fica excluído do livro, como se pode perceber em leitura atenta. Observa-se que a importância de certas imagens, de alguns temas e problemas, e mesmo da linguagem, apregoados pelo Barroco, se faz sentir em muitos momentos do Arcadismo e do Romantismo. Autores como Basílio da Gama, Silva Alvarenga, Gonçalves de Magalhães e Junqueira Freire, por exemplo, retomam de algum modo os pressupostos da poética barroca e quinhentista, manejando-as no sentido de tentar torná-las contemporâneas deles, fazendo-as se misturar com os novos códigos adotados e se exprimir em novo contexto. Assim, o fato de não dispor historicamente da escola barroca, sem destacar e interpretar as obras de seus autores mais ou menos representativos - como faz com o Arcadismo e com o Romantismo - não diminui sua importância no livro, ao contrário. De acordo com isso, digamos que, embora sem destaque, o Barroco é presumido em cada etapa dos momentos decisivos, e pode mesmo ser considerado como o conteúdo sedimentado do processo de constituição e desenvolvimento da literatura no Brasil. Fechando o interregno metodológico, voltemos a Cláudio e sua posição estratégica no processo de acumulação. Ele recebeu forte influência barroca e quinhentista, e chega mesmo a ser considerado como o mais preso à tradição (p. 93, 97); exerceu, entretanto, certa ascendência sobre seus pares, especialmente Gonzaga. Esse, a partir da referida influência, promoveu a consolidação do Arcadismo entre nós, com marcas próprias (p. 113, 123, 146). Basílio da Gama, por sua vez, demonstra uma independência maior, mas permanece credor estético de Cláudio (p. 138), enquanto Silva Alvarenga, sem se desembaraçar desses vínculos (p. 141), encontra uma forma só sua de melodia e ritmo (p. 148). Quanto a Santa Rita Durão, beneficiando-se das conquistas anteriores, revive a linguagem "colorida" do Barroco, carregada de "conceitos e imagens" (p. 190).

Dialeticamente, a força que engendra a depuração da linguagem ao mesmo tempo promove o seu desgaste, fatigando o Arcadismo, exaurindo suas possibilidades de construção e composição. "Sem ruptura radical" (p. 327), o Romantismo vai se constituindo a partir de determinadas soluções formais que o próprio Arcadismo já vinha desenvolvendo de maneira ainda incipiente, mas que somente numa fase posterior poderia amadurecer plenamente. Na ação dos primeiros românticos, o crítico identifica os percalços dessa difícil transição:

Vê-se bem que os rapazes escorregavam nesse terreno de contradições. Anteviam a emergência de uma literatura nova, prevista e augurada por Garret, Denis e outros; ao mesmo tempo, escandalizavam-se com as 
ousadias. Sabiam sentir o arcaísmo das Poesias de Magalhães, mas bradavam ante as novidades do Camões. Queriam e temiam simultaneamente a renovação, em parte porque não tinham dela uma noção definida. [...] Essa contradição é ligada em parte à educação retórica do Classicismo, que se prolongou através de compêndios por todo século XIX, atrapalhando a livre expansão da literatura, propiciando divergência entre sensibilidade e razão. O escritor não recebia, com efeito, dos colégios e dos tratados, elementos para disciplinar a sua inspiração pessoal, uma vez que continuavam a servir-lhe as regras de Aristóteles, Horácio, Bocalino ou Muratori, incompatíveis com a dinâmica do espírito moderno. (p. 319-320)

Tal contradição ganhou forma na obra de Gonçalves de Magalhães (p. 378), mormente considerado o desbravador do movimento romântico no Brasil, mas também em Porto-Alegre (p. 391) e outros. Em Gonçalves Dias, encontramos maior depuração, senso de equilibrio e domínio de uma dicção própria e moderna - isto é, romântica -, ao ponto de se constituir aos poucos em uma referência obrigatória para os mais jovens, "de Junqueira Freire a Castro Alves." (p. 403)

No terreno da prosa ocorreu o mesmo, a começar pelo traquejo aprendido no domínio da forma romance, adquirido, diga-se de passagem, a partir da leitura sistemática e precária de traduções e folhetins (p. 429-437), representando por si só uma forma de acumulação. A prosa de ficção se encontrava à mercê de obras ralas e fracas, de construção difusa, que então circulavam. Elas serão "fundidas e superadas" por Joaquim Manuel de Macedo (p. 441), que, assim, representa um salto qualitativo nesse processo. Esse, contudo e por sua vez, logo mostra sinais de cansaço, exigindo sua própria superação: "o que faltou [a Macedo] foi gosto ou força, para integrar [certos] elementos num sistema expressivo capaz de nos transportar, apresentando personagens carregados daquela densidade que veremos nalguns de Alencar, antes que surgisse a galeria de Machado de Assis." (p. 461)

Esses dois escritores são, aliás, muito valorizados no esquema explicador de Formação. Alencar aparece como o "grande artista da ficção [romântica], dotado não apenas da capacidade básica da narrativa como do senso apurado do estilo. Neste setor os seus defeitos são os do tempo." (p. 546) Devese isso à sua evolução diante do meio cultural e literário em que vivia, do qual, aliás, ela dependia: serve-se dos autores que o precederam e dos contemporâneos; serve-se da própria obra, que vai problematizando passo a passo, variando os temas, calibrando os assuntos; serve-se ainda dos incipientes trabalhos de desvelamento do país, no campo da etnografia, antropologia, naturalismo etc. O 
resultado é um escritor superior em muitos sentidos, um produto cultural de longa história pregressa:

\begin{abstract}
Alencar reconhece a legitimidade nacional das pesquisas essenciais do romance, liberto do pitoresco em benefício do humano social e psicológico; do humano contemporâneo, que nos toca de perto e envolve a sensibilidade com os seus problemas. Não se trata mais, com efeito, de ser brasileiro à Chateaubriand, o que no fundo é aceitar uma visão de estrangeiro, inclinado a ver o exótico e, confinando a ele os escritores, negar-lhes acesso aos grandes temas universais que o Neoclassicismo implantara aqui. Trata-se de descrever e analisar os vários aspectos de uma sociedade, no tempo e no espaço, exprimindo a sua luta por autodefinição nacional como povo civilizado, ligado ao ciclo de cultura do Ocidente. (p. 680)
\end{abstract}

A poética do romance elaborada por Alencar inspira e mede as conquistas de Bernardo Guimarães (que ainda apresentava cacoetes neoclássicos [p. 441]), Taunay (e, através dele, Euclides da Cunha [p. 623]), Manuel Antonio de Almeida e Franklin Távora (por meio de quem se alcança Gilberto Freyre, José Lins do Rego e Graciliano Ramos [p. 617]). Não obstante essa evolução, e como as leis da dialética são implacáveis, a poética do romance também começa a dar sinais de fadiga, criando as possibilidades de surgimento de Machado de Assis.

O aprofundamento da análise vai-se tornando viável pela sedimentação do material estudado no romance extensivo. O romance rural de Bernardo e Távora; o romance urbano de Macedo, Manuel Antonio e Alencar (mais refinado na análise à medida que a burguesia ia se ampliando e diversificando como classe) constituem por assim dizer a superposição progressiva de camadas, que ia consolidando o terreno para a sondagem profunda de Machado de Assis. (p. 434)

Abrindo parênteses para comentar o enquadramento do livro e sua opção metodológica, nota-se que, apesar de sua incontestável importância, Machado não recebe um capítulo específico para a análise de sua obra. Penso que podemos comparar essa ausência com a de Gregório de Matos, que tanto despertou a grita de alguns estudiosos de Formação. ${ }^{8}$ A explicação, se eu não estiver enganado,

8. Destaco apenas os seguintes trabalhos: COUTINHO. Conceito de literatura brasileira; e CAMPOS. O seqüestro do Barros na Formação da literatura brasileira: o caso Gregório de Mattos. 
consiste na perspectiva adotada, voltada à análise dos momentos decisivos do processo de formação, isto é, quando o caráter congruente e produtivo da prática letrada no Brasil estava ainda constituindo as bases de retroalimentação da linguagem literária propriamente dita. Nesse enquadramento - que é analítico, mas aparece historicamente - os dois grandes escritores se encontram excluídos, o primeiro porque tal caráter ainda não havia se consolidado, o segundo porque o seu ciclo de amadurecimento já havia se completado. Mas é preciso frisar que, na condição de precursor, Gregório foi um pressuposto desse processo, enquanto Machado, um resultado seu.

Voltando ao "sistema", vemos que os escritores e suas obras vão se imiscuindo, numa dinâmica que inclui os mais e os menos importantes, dos quais, aliás, aqueles dependem. Obras de maior ou menor expressão, escritores melhor dotados de talento ou não, tudo converge, mesmo que de maneira desigual, e concorre no trajeto de amadurecimento e depuração da forma artística. Não existe aqui - destaque-se - nenhum juízo de valor, como apregoam alguns críticos, mas sim um juízo estético. O leitor perceberá que toda explicação desse processo se dá por meio de contradição dialética: certos problemas (temas, imagens, estilo, linguagem) se contrapõem entre si, fazendo daí surgir impasses formais, que, em seu próprio tempo ou posteriormente, vão apurando. Tome-se a passagem abaixo como exemplo:

Sob vários aspectos, sentimos em Alencar a percepção complexa do mal, do anormal ou do recalque, como obstáculos à perfeição e como elemento permanente na conduta humana. É uma manifestação da dialética do bem e do mal que percorre toda ficção romântica, inclusive a nossa. No menos característico Manuel Antonio de Almeida, vimos que não existe; em Bernardo, ela se atenua, sob a influência de um otimismo natural e sadio. Em Teixeira e Sousa e em Macedo, aparece como luta convencional dos contrários, para atingir, em Alencar, um refinamento que pressagia Machado de Assis. (p. 545)

Mais uma vez vale lembrar que, para chegar a essa fórmula, Antonio Candido não partiu de pressupostos teóricos ou historiográficos, mas da análise formal das obras. Essa característica, tão simples e tão difícil de lograr também, em minha opinião, constitui-se como a principal linha de força do livro. 


\section{Últimas questões}

Formação da literatura brasileira foi escrita para ser um livro de história - e é de fato - mas com perspectiva crítica e interesse acentuado pela análise. Esse dado, a princípio banal, traz consequências relevantes para o campo teórico, que, entretanto, não são compreendidas prontamente. Na articulação entre reconstrução histórica e análise crítica, ora a explicação pende mais para um lado e ora pende mais para o outro, e nisso consiste a razão de seu equilíbrio. Percebendo os motivos de compreensão travada de seu método, o autor escreve um prefácio para a segunda edição do livro, em que esclarece: "Este ângulo de visão requer um método que seja histórico e estético ao mesmo tempo, mostrando, por exemplo, como certos elementos da formação nacional (dado histórico-social) levam o escritor a escolher e tratar de maneira determinada alguns temas literários (dado estético)." (p. 18) Para o bem ou para o mal, o princípio histórico ou o teórico parece ter se sobreposto ao crítico ${ }^{9}$ - quando, na verdade, é seu resultado. Além disso, como se sabe, o autor se colocou ao lado dos primeiros críticos românticos, assumindo em muitos aspectos o seu ângulo de visão. Todavia, o que nem todos perceberam foi que ele os "superou", dialeticamente falando. Nesse sentido, vale a pena ler com atenção o último capítulo do livro, "A consciência literária" (p. 635-681): o autor nos expõe a tradição crítica e historiográfica que estava se constituindo; destaca os pontos fortes, que se desenvolveram e se transformaram, e os fracos, que minguaram; apresenta os homens que com dificuldade e esforço foram colaborando para erigir essa tradição; por fim, explica e interpreta suas ideias. Antonio Candido se impregnou dessa cadeia, recebendo, avaliando, alterando e depurando ele mesmo a contribuição desses homens de Letras (Santiago Nunes Ribeiro, Pereira da Silva, Joaquim Norberto, Silvio Romero e José Veríssimo, além de Garret, Denis, Chateaubriand e muitos outros). Formação não apenas recupera e avalia esse legado, como também, e, sobretudo, se liga a ele. O reconhecimento da relevância do livro, apreciado em contexto, depende da compreensão da tradição que o precede, mas não só. Penso que é enriquecedor pô-lo em relação com os livros "formadores", que podemos considerar como seus contemporâneos, embora alguns o precedam em mais de vinte anos: Casa grande E senzala (1933), Raízes do Brasil (1936) e Formação do Brasil contemporâneo (1942). Respeitando as

9. Nessa direção, ver: LIMA. Concepção de história literária na Formação; e BAPTISTA. O cânone como formação: a teoria da literatura brasileira de Antonio Candido, além dos já citados, Afrânio Coutinho e Haroldo de Campos. 
considerações do próprio Candido, ${ }^{10}$ certamente em um de seus conhecidos momentos de modéstia, ponho-me, contudo, ao lado daqueles que viram paridade entre esses livros e Formação. Neste, encontramos a compreensão orgânica dos modos de vida (tal como no livro de Gilberto Freyre), integrando nela a literatura; deparamo-nos com o sentimento dos contrários moldando nossa existência material e espiritual (captado por Sérgio Buarque); e enfrentamos a árdua, mas interessante engenhoca analítica chamada "sistema" (assim como em Caio Prado), como forma de internalizar e tornar próprio e orgânico o que vinha por pressão externa.

O valor de Formação, cuja notabilidade é amplamente reconhecida, deve ser destacado, mas sem que se perca de vista o que talvez venha a ser sua maior contribuição: ensinar aos jovens - universitários ou não - a apreciar a literatura brasileira com inteligência e espírito crítico bem armado, encarando-a como meio de reconhecimento das coisas que lhes dizem respeito. Para além do refinamento e da erudição que traz, o livro continua sendo isso e muito mais.

\section{Título:}

Abstract: This study aims at analyzing the work by Antonio Candido, Formação da literature brasileira, based on its global articulation, stressed bay the combination points and coherent expounding. Keywords: Literary Criticism, Historiography, Dialectics

10. Ver entrevista de Antonio Candido no final deste volume. 


$$
\text { Referências }
$$

ARANTES, Paulo Eduardo. Providências de um crítico literário na periferia do capitalismo. In: D'INCAO, Maria Ângela; SCARABÔTOLO, Eloísa Faria (Org.). Dentro do texto, dentro da vida: ensaios sobre Antonio Candido. São Paulo: Companhia das Letras; Instituto Moreira Salles, 1992. p. 229-261.

ARANTES, Paulo Eduardo. Providências de um crítico literário na periferia do capitalismo. In: ARANTES, Otília Beatriz Fiori; ARANTES, Paulo Eduardo. Sentido de formação: três estudos sobre Antonio Candido, Gilda de Mello e Souza e Lúcio Costa. São Paulo: Paz e Terra, 1997. p. 7-66.

ARRIGUCCI Jr., David. Movimentos de um leitor. In: D'INCAO, Maria Ângela; SCARABÔTOLO, Eloísa Faria (Org.). Dentro do texto, dentro da vida: ensaios sobre Antonio Candido. São Paulo: Companhia das Letras; Instituto Moreira Salles, 1992. p. 181-204.

BAPTISTA, Abel Barros. O cânone como formação: a teoria da literatura brasileira de Antonio Candido. In: O livro agreste: ensaio de curso de literatura brasileira. Campinas: Ed. Unicamp, 2005.

CANDIDO, Antonio. Formação da literatura brasileira: momentos decisivos. 10. ed. Rio de Janeiro: Ouro sobre Azul, 2006.

CANDIDO, Antonio. Tese e antítese. 4. ed. São Paulo: T.A. Queiroz, 2002.

CANDIDO, Antonio. Literatura e sociedade. 7. ed. São Paulo: Ed. Nacional, 1985.

CAMPOS, Haroldo de. O sequestro do barroco na Formação da literatura brasileira: o caso Gregório de Mattos. Salvador: Fundação Casa de Jorge Amado, 1989.

COUTINHO, Afrânio. Conceito de literatura brasileira. Rio de Janeiro: Acadêmica, 1960.

JACKSON, Luiz Carlos. A tradição esquecida: os parceiros do Rio Bonito e a sociologia de Antonio Candido. Belo Horizonte: EdUFMG, 2002.

LIMA, Luiz Costa. Concepção de história literária na Formação. In: Pensando nos trópicos. Rio de Janeiro: Rocco, 1991.

LIMA, Luiz Costa. Concepção de história literária na Formação. In: D’INCAO, Maria Ângela; SCARABÔTOLO, Eló́sa Faria (Org.). Dentro do texto, dentro da vida: ensaios sobre Antonio Candido. São Paulo: Companhia das Letras; Instituto Moreira Salles, 1992, p.153-169.

SCHWARZ, Roberto. Os sete fôlegos de um livro. In: Sequências brasileiras. São Paulo: Companhia das Letras, 1999, p. 46-58.

SCHWARZ, Roberto. Os sete fôlegos de um livro. In: AGUIAR, Flávio (Org.). Antonio Candido: pensamento e militância. São Paulo: Fundação Perseu Abramo; Humanitas, 1999, p. 82-95.

WAIZBORT, Leopoldo. A passagem do três ao um: crítica literária, sociologia, filologia. São Paulo: Cosac Naify, 2007. 